\title{
Effect of Moisture Content on Physical Properties of Black Pepper
}

\author{
R. Shreelavaniya* and S. Kamaraj \\ Department of Bioenergy, Agricultural Engineering College and Research Institute, Tamil Nadu \\ Agricultural University, Coimbatore 641 003, Tamil Nadu, India \\ *Corresponding author
}

Keywords

Piper nigrum,

Physical properties,

Moisture content,

Bulk density, Porosity.

Article Info

Accepted:

29 September 2017

Available Online:

10 October 2017

\section{A B S T R A C T}

The paper presents the physical properties of freshly harvested and dried black pepper (Piper nigrum). The physical properties of black pepper in the moisture range of 81.3 - $8.65 \%$ (w.b.) were determined. The length, breadth, thickness, sphericity, thousand capsule mass, porosity, true density and angle of repose were investigated and was found to increase with increase in moisture content whereas bulk density and hardness decreased with the increase of moisture content. The highest static coefficient of friction was observed on mild steel surface, followed by aluminium sheet, galvanized iron sheet and stainless steel sheet. The physical properties of black pepper were expressed in the form of regression equations as a moisture content function.

\section{Introduction}

In order to design equipment for drying, storing, grading and processing the black pepper their physical properties should be known. Their size and shape, for instance, are important in the development of grading machines. Bulk density and porosity are needed in designing near ambient drying and aeration systems, because these properties affect the resistance to airflow of the stored mass. The theories used to predict the structural loads for storage structures use bulk density as a basic parameter. The friction coefficient of the capsules on various surfaces helps in designing bins, silos and other storage structures. The angle of repose is important in designing equipment for solid flow structures for storage. The objective of this study was to investigate the physical properties of black pepper namely, size, sphericity, bulk density, true density, porosity, angle of repose, coefficient of friction, thousand capsule mass and hardness in the moisture content range from $81.3-8.65 \%$ (w.b).

\section{Materials and Methods}

Freshly harvested Black pepper, Piper nigrum (Panniyur-I variety) procured from Horticultural Research Station, Thadiyankudisai, Dindigul district, Tamil Nadu was used for this experiment. 
Immediately after harvesting the spike from vines, they were trampled to separate the pepper berries from spikes. The freshly harvested black pepper was manually cleaned to remove foreign materials. The initial moisture content was found as $81.3 \%$ (w.b.) after harvesting. Experiments were conducted in the moisture range of $81.3-8.65 \%$ (w.b.).

The mean capsule size $\left(d_{p}\right)$ and sphericity $(\phi)$ were determined by picking twenty capsules randomly and measuring their three principal dimensions using vernier caliper having a least count of $0.01 \mathrm{~mm}$ (Mohsenin, 1980; Tabatabaeefar, 2003; Koocheki et al., 2007). The mass was determined by randomly selecting 100 capsules and weighing in an electronic balance of $0.01 \mathrm{~g}$ sensitivity. The mass was then converted into 1000 capsule mass $\left(W_{1000}\right)$. The bulk density $(\varrho b)$ of black pepper was determined by filling a circular container of known volume and weighing the content.

During the experiment, care was taken to avoid any compaction of the material in the container. Bulk density was calculated as the ratio between the mass of black pepper and the container volume. At each moisture level, five replications were carried out and the average values were reported. The porosity (E) was calculated from the values of true density and bulk density (Ozguven and Vursavus, 2005). The angle of repose $(\Theta)$ for the black pepper capsules was determined from the height and diameter of the naturally formed heap of seeds on a circular plate (Kingsly et al., 2006). The coefficient of friction $(\mu)$ was determined with respect to four test surfaces, namely; stainless steel (SS), galvanized iron (GI), mild steel $(M S)$ and aluminium $(A l)$ using the experimental setup according to Jha and Kachru (1998). The hardness $(h)$ of black pepper was measured using texture analyzer (TA-Hdi, Stable Microsystems, UK) (Sajeev et al., 2004).

\section{Results and Discussion}

\section{Size}

The size of Black pepper berries $\left(d_{p}\right)$ at different moisture content is presented in Figure 1. The length, breadth and thickness increased from 4.90 to $5.35 \mathrm{~mm}, 4.55$ to 5.03 $\mathrm{mm}$ and 4.38 to $4.87 \mathrm{~mm}$ respectively with increase in moisture content [Eq. (1), (2) and (3)].

The dimension of Black pepper increased with increase in moisture content due to absorption of moisture that resulted in swelling of capillaries and expressing expansion in major, medium and minor axes along with the geometric mean diameter. Similar results have been reported by Karababa (2006) for popcorn kernel.

Length $=4.928+0.005 M C\left(\mathrm{R}^{2}=0.903\right)$

Breadth $=4.352+0.008 M C\left(\mathrm{R}^{2}=0.906\right) \ldots \ldots$ (2)

Thickness $=4.323+0.007 M C\left(\mathrm{R}^{2}=0.929\right) . .(3)$

\section{Sphericity}

The sphericity of the pepper berries $(\phi)$ increased linearly from 0.938 to 0.949 as the moisture content increased from 8.65 to $81.3 \%$ (w.b.) [Eq. (4)] (Fig. 1). Similar results were reported by Solomon and Zewdu (2009) for niger berries.

$\phi=0.936+0.000 M C\left(\mathrm{R}^{2}=0.994\right)$.

\section{Thousand capsule mass}

The mass of 1000 capsules $\left(W_{1000}\right)$ increased from 42.5 to $56.9 \mathrm{~g}$ with the increase of moisture content [Eq. (5)] (Fig. 2). Similar trends were reported by Singh and Goswami (1996) and Altuntas et al., (2005) for cumin and fenugreek berries, respectively.

$\mathrm{W}_{1000}=40.10+0.205 M C\left(\mathrm{R}^{2}=0.990\right) \ldots \ldots(5)$ 


\section{Porosity}

The values of porosity $(\varepsilon)$ were calculated by using the data of bulk and true densities of the pepper berries. The results obtained are presented in Figure 2.

The porosity of the pepper berries increased linearly from $43.2 \%$ to $46.7 \%$ with increase in moisture content [Eq. (6)]. Similar trend of porosity of black pepper berries and other grains was reported by Altuntas et al., (2005) and Coskuner and Karababa (2007).

$\varepsilon=42.90+0.047 M C\left(\mathrm{R}^{2}=0.994\right)$.

\section{Bulk density and true density}

The variation in bulk density $\left(\rho_{b}\right)$ and true density $\left(\rho_{t}\right)$ with moisture content is shown in Figure 3. The bulk density of black pepper berries was found to decrease linearly whereas the true density increased with increase in moisture content [Eqs (7) and (8)]. $\rho_{b}=561.3-0.255 M C\left(\mathrm{R}^{2}=0.995\right)$

$\rho_{t}=982.6+0.337 M C\left(\mathrm{R}^{2}=0.994\right)$

The bulk density was found to vary from 558.52 to $540.84 \mathrm{~kg} / \mathrm{m}^{3}$. The decrease in bulk density with an increase in moisture content is mainly due to the increase in volume than the corresponding increase in mass of the material.

It facilitates the same mass of material to occupy more volume of the cylinder thus decreasing the bulk density. Similar trend of decrease in bulk density has been reported by Coskuner and Karababa (2007) for coriander seed. The true density increased from 985.1 to $1010.2 \mathrm{~kg} / \mathrm{m}^{3}$ as the moisture content increased.

This increase may be due to the increase in volume due to absorption of moisture. The same trend has been reported by Altuntas $e t$ al., (2005) and Coskuner and Karababa (2007).

Fig.1 Effect of moisture content on size and sphericity of black pepper

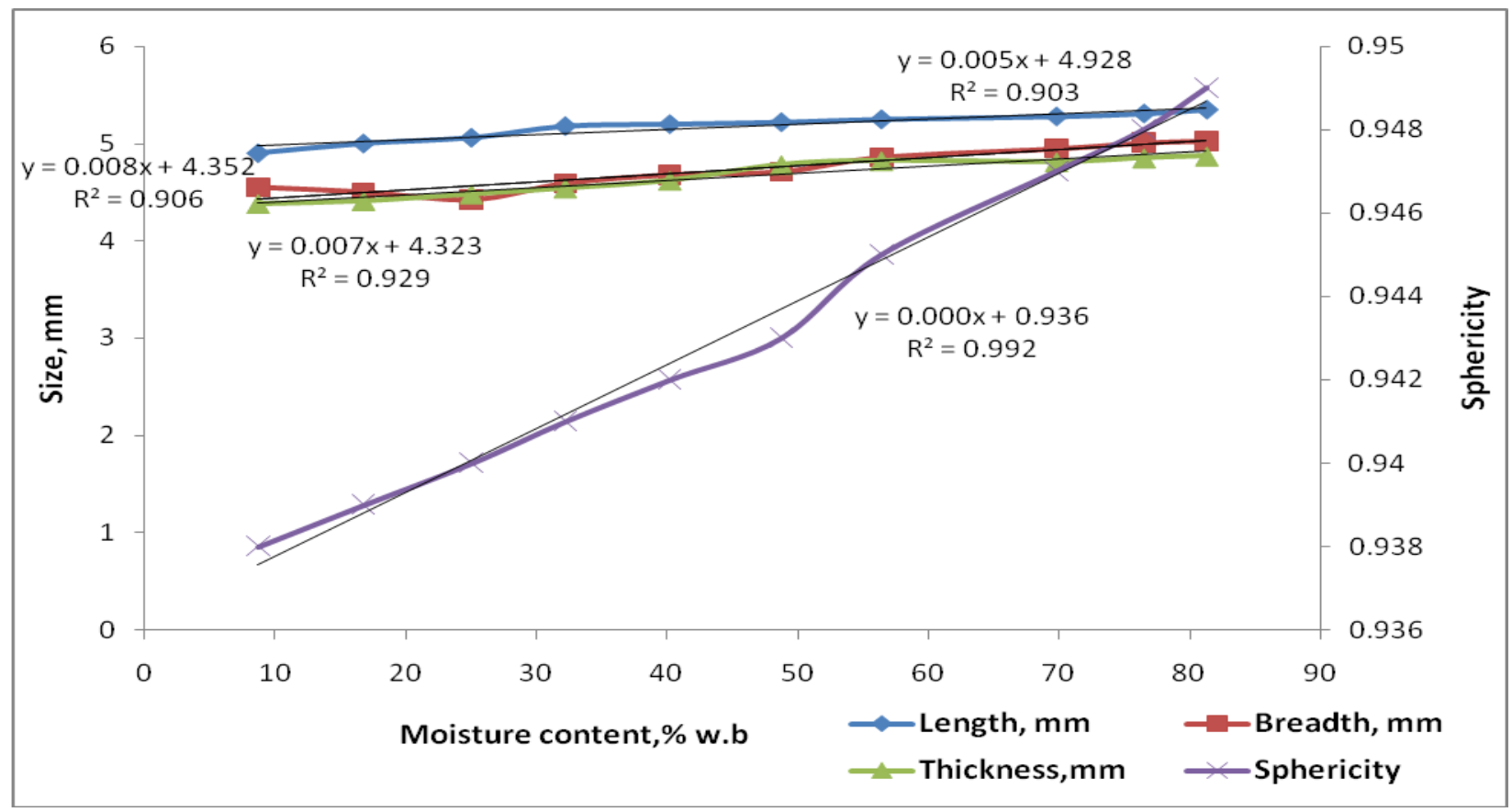


Fig.2 Effect of moisture content on thousand capsule mass and porosity

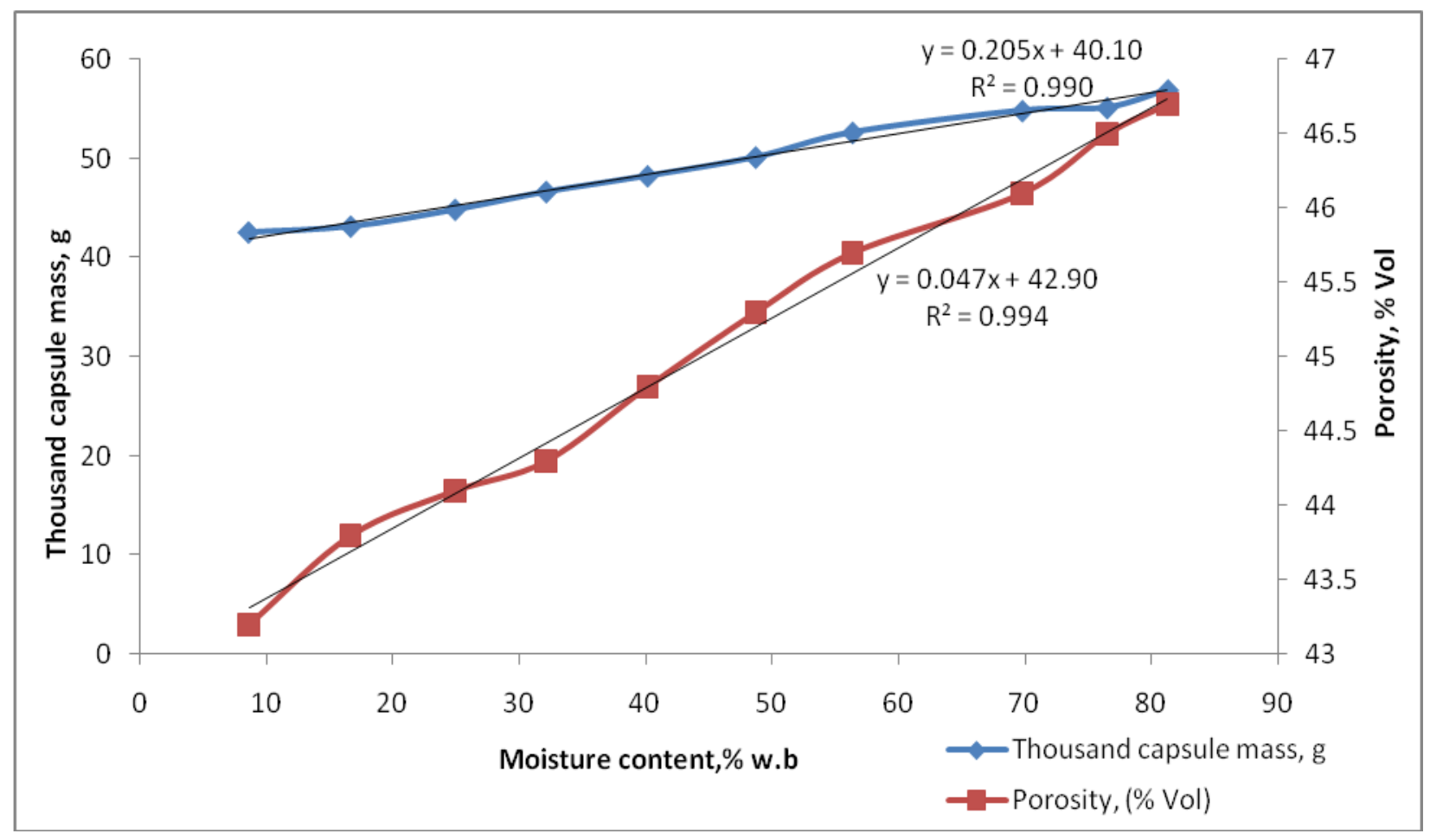

Fig.3 Effect of moisture content on bulk density and true density

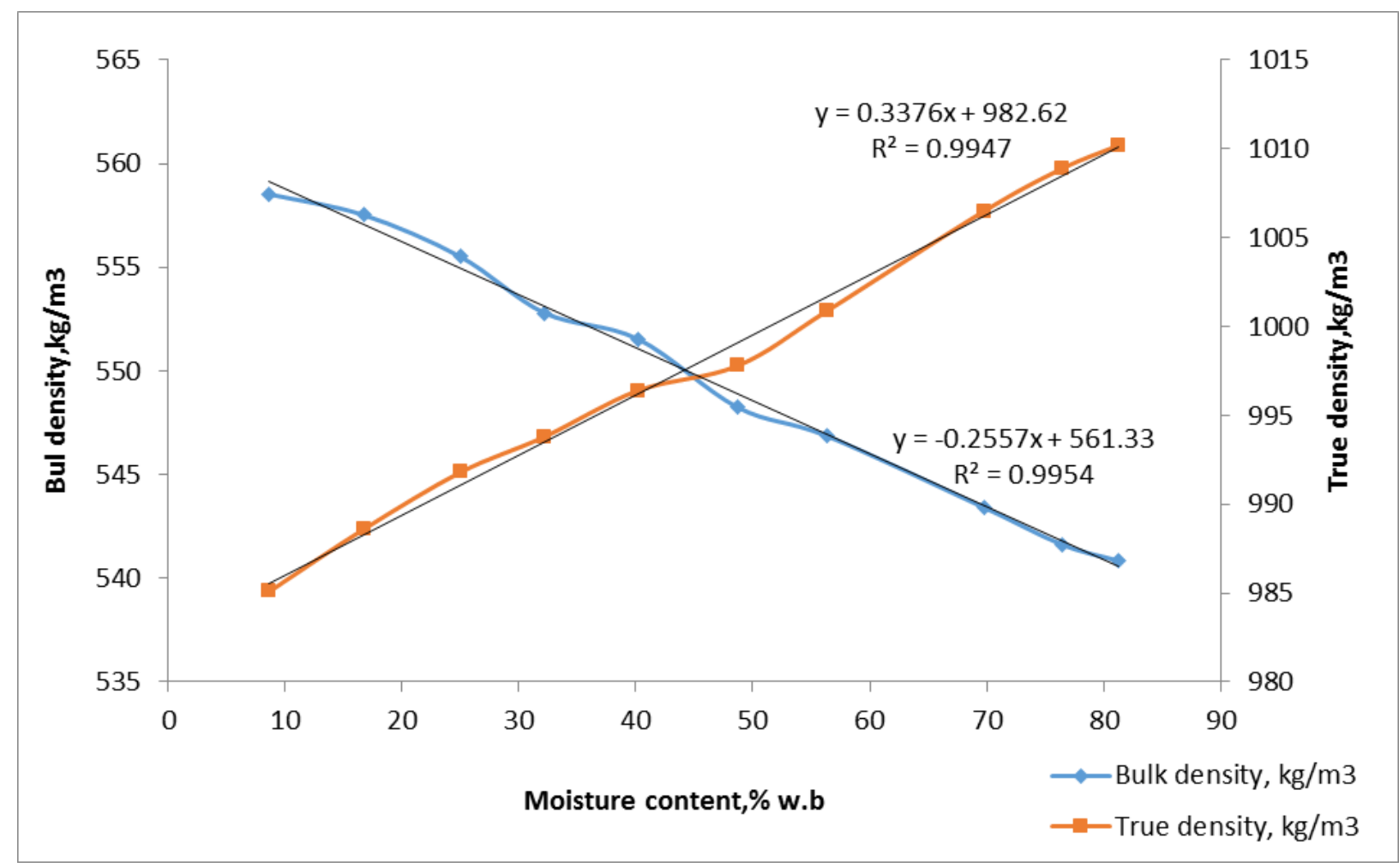


Fig.4 Effect of moisture content on angle of repose and hardness

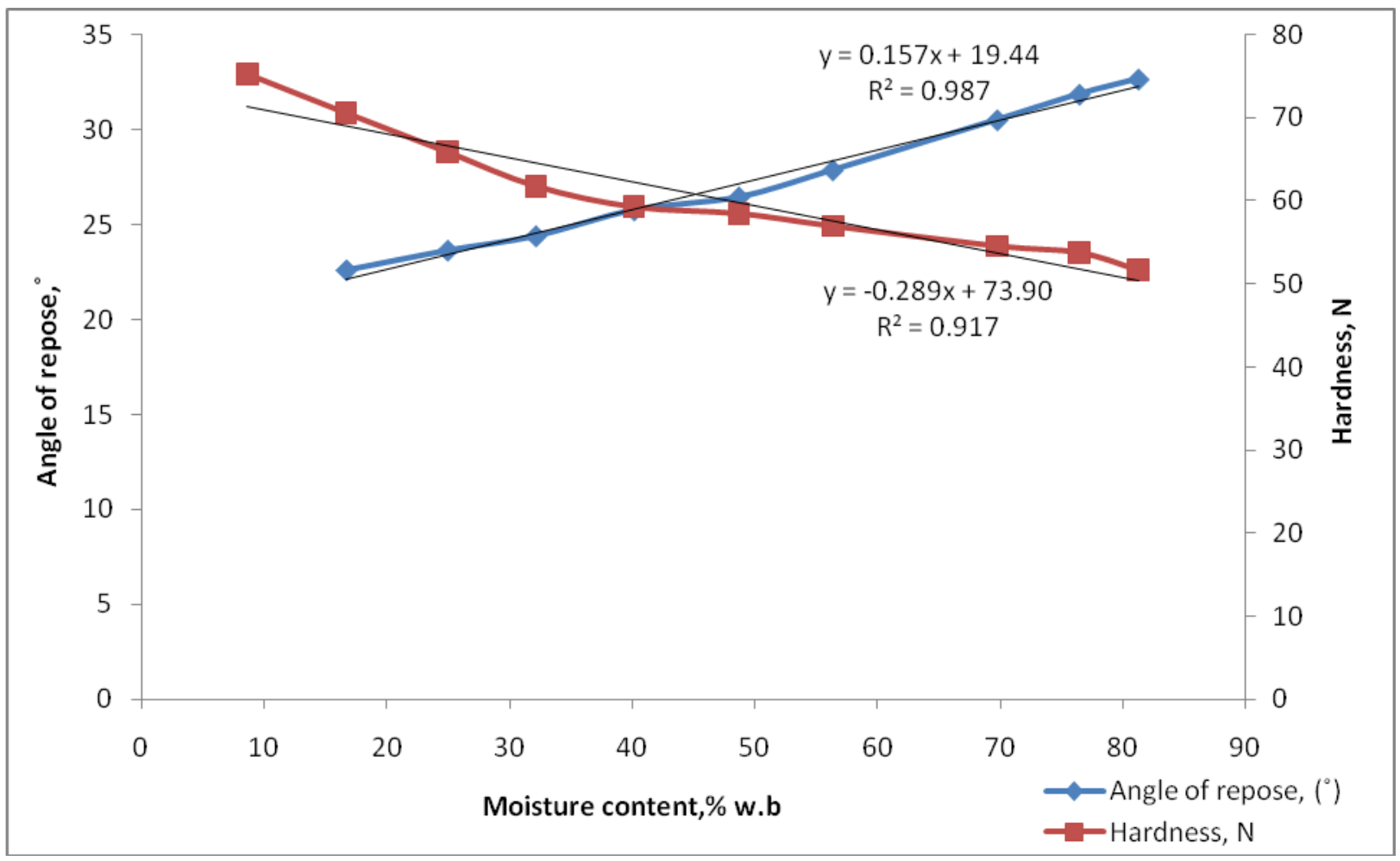

Fig.5 Effect of moisture content on coefficient of friction

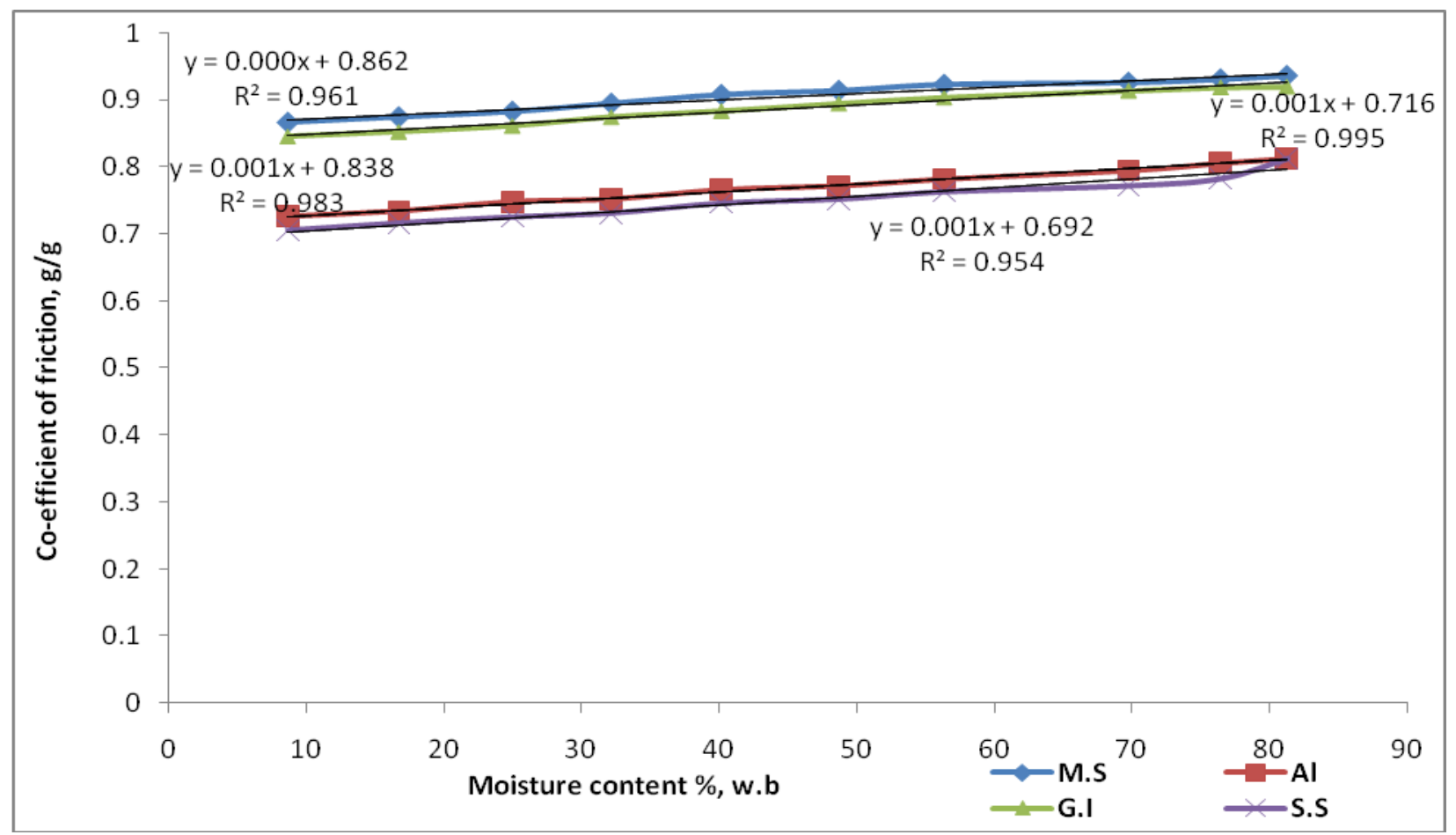




\section{Angle of repose}

The experimental results for angle of repose $(\Theta)$ with respect to moisture content are shown in Figure 4. It was observed that the angle of repose increased linearly from $22.25^{\circ}$ to $32.65^{\circ}$ with increase in the moisture content [Eq. (9)]. Most of the biological materials appear to exhibit an increase in angle of repose with higher moisture content (Mohsenin, 1980) and the present study also follows a similar pattern. The trend of increase in angle of repose with moisture content is similar to that reported by Altuntas et al., (2005) for fenugreek and by Coskuner and Karababa (2007) for coriander berries.

$\Theta=19.44+0.157 M C\left(\mathrm{R}^{2}=0.987\right)$

\section{Hardness}

The hardness $(h)$ as affected by the moisture content is presented in Figure 4. The hardness decreased linearly from $75.2 \mathrm{~N}$ to $51.6 \mathrm{~N}$ with the increase in moisture content [Eq. (10)]. The decrease in hardness may be due to the fact that at higher moisture content, the inner core of berry becomes markedly softer and requires less force, whereas at the lower moisture content, only the outer coat of berry absorbs moisture and requires higher force. Similar findings have been reported by Saiedirad et al., (2008) for cumin and Murthy and Bhattacharya (1998) for black pepper berry.

$\mathrm{h}=73.90-0.289 M C\left(\mathrm{R}^{2}=0.917\right)$

\section{Coefficient of friction}

The effect of moisture on Black pepper berries on the coefficients of friction against the various test surfaces viz., mild steel sheet (MS), aluminium sheet ( $\mathrm{Al}$ ), galvanized iron sheet (GI) and stainless sheet (SS) is given in Figure 5. The coefficient of friction increased linearly with moisture content for all contact surfaces. The static coefficient of friction ranged from 0.867 to $0.936,0.846$ to 0.920 , 0.726 to 0.813 and 0.705 to 0.813 , respectively for mild steel sheet, galvanized iron sheet, aluminum sheet and stainless steel sheet as the moisture content increased. It was found that, the coefficient of static friction on MS sheet was higher than GI sheet, Al sheet, and SS sheet [Eqs (11), (12), (13) and (14)].

$\mu_{\mathrm{MS}}=0.862+0.000 M C\left(\mathrm{R}^{2}=0.961\right)$

$\mu_{\mathrm{Al}}=0.838+0.001 M C\left(\mathrm{R}^{2}=0.983\right)$

$\mu_{\mathrm{GI}}=0.716+0.001 M C\left(\mathrm{R}^{2}=0.995\right) \ldots \ldots .(13)$

$\mu_{\mathrm{ss}}=0.692+0.001 M C\left(\mathrm{R}^{2}=0.954\right) \ldots \ldots(14)$

Static coefficient of friction increased with increase in moisture content on all four surfaces. The lower value of coefficient of friction in the case of stainless steel was due to the smooth and polished surface of the stainless steel sheet compared with other test surfaces used. It may be because, at higher moisture contents, the berries become rougher and sliding characteristics are diminished, so that the static coefficient of friction increases. Similar results were found by other researchers for coriander (Coskuner and Karababa, 2007).

The following conclusions are drawn from the investigation on physical properties of black pepper. The length, breadth, thickness, sphericity, thousand capsule mass, porosity, true density and angle of repose ranging from 4.90 to $5.35 \mathrm{~mm}, 4.55$ to $5.03 \mathrm{~mm}, 4.38$ to $4.87 \mathrm{~mm}, 0.938$ to $0.949,42.5$ to $56.9 \mathrm{~g}, 43.2$ to $46.7 \%$ vol, 985.1 to $1010.2 \mathrm{~kg} / \mathrm{m}^{3}, 22.25^{\circ}$ to $32.65^{\circ}$ respectively. As the moisture content increased, the bulk density and hardness were found to decrease from 558.52 to $54.084 \mathrm{~kg} / \mathrm{m}^{3}$ and $75.2 \mathrm{~N}$ to $51.6 \mathrm{~N}$ respectively. The highest coefficient of friction was noted on mild steel followed by galvanized iron sheet, aluminium sheet and stainless steel sheet. 


\section{Acknowledgment}

Authors are highly indebted to Tamil Nadu Agricultural University, Coimbatore, India for providing necessary facilities.

\section{References}

Altuntas, E., E. Ozgoz and F. Taser. 2005. Some physical properties of fenugreek (Trigonella foenum-graceum L.) seeds. J. Food Engg. 71:37-43.

Balasubramanian, S., R. Sharma, and V.Sardana. 2001. Studies on some engineering properties of peanut pod and kernel. Agricultural Engineering, 48(2):38-42.

Coskuner, Y. and E. Karababa. 2007. Physical properties of coriander seeds (Coriandrum sativum L.). J. Food Engg., 80:408-416.

Gupta, R.K., and S.K. Das. 1997. Physical properties of sunflower seeds. Journal of Agricultural Engineering Research, 66(1):18.

Jha S.N. and Kachru R.P., 1998. Physical and aerodynamic properties of makhana. J. Food Proc. Eng. 21, 301-316.

Joshi, D. C., S.K. Das, and K.R. Mukherjee. 1993. Physical properties of pumpkin seeds. Journal of Agricultural Engineering Research, 54(3):219-229.

Karababa, E. 2006. Physical properties of popcorn kernels. J. Food Engg., 72:100-107.

Kiani, D.K.M., S. Minaei, H. Maghsoudi and M. Ghasemi Varnamkhasti. 2008. Moisture dependent physical properties of red bean (Phaseolus vulgaris L.) grains. Int. Agrophysics, 22:231-237.

Kingsly A.R.P., Singh D.B., Manikantan M.R., and Jain R.K., 2006. Moisture dependent physical properties of dried pomegranate seeds (Anardana). J. Food Eng.75, 492-496.

Koocheki A., Razavi S.M.A., Milani E.,
Moghadan T.M., Abedini M., Alamatiyan S., and Izadikhah S., 2007. Physical properties of watermelon seed as a function of moisture content and variety. Int. Agrophysics. 21, 349-359.

Mohsenin, N.N. 1980. Physical Properties of Plant and Animal Materials. Gordon and Breach Press, New York, USA.

Murthy, C.T. and S. Bhattacharya. 1998. Moisture dependant physical and uniaxial compression properties of black pepper. $J$. Food Engg. 37:193-205.

Ozguven F., and Vursavus K., 2005. Some physical, mechanical and aerodynamic properties of pine (Pinus pinea) nuts. $J$. Food Eng. 68, 191-196.

Saiedirad, M. H., A. Tabatabaeefar, A. Borghei, M. Mirsalehi, F. Badii and V.M. Ghasemi. 2008. Effects of moisture content, seed size, loading rate and seed orientation on force and energy required for fracturing cumin seed (Cuminum cyminum L.) under quasistatic loading. J.Food Engg., 86:565-572.

Sajeev M.S., Manikantan M.R., Kingsly A.R.P., Moorthy S.N., and Sreekumar J., 2004. Texture analysis of taro (Colocasia esculenta L. Schott) cormels during storage and cooking. J. Food Sci. 69, E315-E321.

Singh, K.K. and T.K. Goswami. 1996. Physical properties of cumin seed. J. agric. Engng. Res., 64: 93-98.

Solomon, W. K. and A.D. Zewdu. 2009. Moisturedependent physical properties of niger (Guizotia abyssinica Cass.) seed. Indl. Crops Prod., 29:165-170.

Tabatabaeefar A., 2003. Moisture-dependent physical properties of wheat. Int. Agrophysics.17, 207-211.

Viswanathan, R., P.T. Palanisamy, L. Gothandapani and V.V. Sreenarayanan. 1996. Physical properties of neem nut. $J$. Agric. Eng. Res., 63:19-26.

\section{How to cite this article:}

Shreelavaniya, R. and Kamaraj, S. 2017. Effect of Moisture Content on Physical Properties of Black Pepper. Int.J.Curr.Microbiol.App.Sci. 6(10): 4873-4879.

doi: https://doi.org/10.20546/ijcmas.2017.610.456 